\title{
Register of Events in Rheumatology: 1980
}

January

$\begin{array}{ll}\text { 20th-25th } & \text { IV Congress of SEAPAL-AR } \\ \text { February } & \\ \dagger & \begin{array}{l}\text { European Biological Research Association-'Future } \\ \text { Trends in Inflammation: IV' }\end{array}\end{array}$

April

10th-12th British Orthopaedic Association-Spring Meeting

25th-26th Association of Physicians of Great Britain and Ireland-Annual Meeting

May

23rd-27th VIII International Congress of Physical Medicine and Rehabilitation: 'Disability, Prevention and Medical Rehabilitation'

June

22nd-27th 1980 World Congress of Rehabilitation International-'Prevention integration: Priorities for the ' 80 's

\author{
August \\ 17th-22nd \\ September \\ 25th-27th \\ Royal Microscopical Society-MICRO '80 \\ Heberden Society/BARR/Royal Society of Medicine \\ Section of Rheumatology and Rehabilitation- \\ Annual Provincial Meeting \\ $\dagger$ Date to be confirmed.
}

Manilla, Philippines

Grosvenor Hotel, London

University of Kent, Canterbury

London

Stockholm, Sweden

Winnipeg Convention Centre, Winnipeg, Canada

Brighton

\section{Tests for lymphocyte function}

Sir,

Percy et al. (1978) claim to have demonstrated a relationship between clinical improvement and increased responsiveness to PHA. Of their patients with initial PHA hyporesponsiveness whose PHA test improved 11 improved clinically and 2 did not, whereas in the 2 whose PHA remained low 1 improved clinically and the other did not. The 2-way contingency table shows this distribution to have a $\mathbf{P}=\mathbf{0} \cdot 34$. Another interpretation of their results is that in patients with initially low PHA response the PHA test tends to improve no matter what happens clinically. In tests with widely variable results, like PHA responsiveness, very low results are apt to improve on retesting, as 2 consecutive low values would be unusual. This 'regression towards the mean' is a less exciting interpretation but could be tested by restudying the normal controls with low initial results. Should these values improve, then PHA improvement in the rheumatoid arthritis group could be related to the probability that abnormal results of variable tests tend to normalise rather than that treatment has induced amelioration of an immune defect. New York 13210, USA

\section{Reference}

Percy, J. S., Davis, P., Russell, A. S., and Brisson, E. (1978). A longitudinal study of in vitro tests for lymphocyte function in rheumatoid arthritis. Annals of the Rheumatic Diseases, 37, 416-420.

Sir,

We are interested by Dr Runge's comments, but we believe that it is logically invalid to test a subset of data by a $2 \times 2$ contingency when these data are extracted from results which were collected according to a $2 \times 3$ experimental design. Furthermore, his $P$ value of 0.34 would appear to be based on a comparison between 12 observations and 3 observations, which figures we consider to be too small for any analysis.

Initially low PHA responses usually do improve in normal subjects, but this has never been shown to be the case in patients with rheumatoid arthritis. If $\mathrm{Dr}$ Runge has any data to support this suggestion we would urge him to publish them. Our own, as yet unpublished, observations on a second cohort of treated patients would seem to be in direct contradiction to his view.

JoHn PerCy Clinical Sciences Building, University of Alberta, Edmonton, Alberta, Canada 